by adding Io cc. of the reagent to a tube of distilled water and then adding standard copper solution in $0.2 \mathrm{cc}$. portions until the colors of the two tubes match. If one litre of water were originally taken, each cubic centimeter of standard solution used represents 0.2 part per million of copper.

The method has been carefully tested as to the completeness of the separation and as to the influence of other substances in the water. Particular care has been taken to separate small amounts of copper from large amounts of organic matter (sewage and industrial wastes), coloring-matter in surface waters, and from salts of iron, lead, silver and tin. As will be seen from the appended table of results the separation is in all cases satisfactory. Silver and tin appear to be, according to the authorities, the only metals which will separate out under the conditions used. Neither will be commonly met with. The silver may be converted into the chloride as indicated and does not interfere with the determination. The tin is only partially dissolved by the nitric acid and during the evaporation is converted into metastannic acid. In the alkaline solution used in the test the tin in this form does not interfere in the least.

In the accompanying table are given the results obtained in testing this method. In all cases except those in which Boston sewage and straw-board liquor (the waste liquor of a straw-board mill) were used, one litre of water was taken and the necessary solutions added to it. In the two cases mentioned only roo cc. were taken.

SANITARY RESEARCH LABORATORY, Mass. INST, OF TECH.

\title{
SOME INVESTIGATIONS ON SALTS OF CASEIN."
}

BY J. H. LONG.

Received January I, Igo6.

THE question of the identity of caseins from different kinds of milk is an old problem for which the complete solution appears to be still some distance in the future. Even superficial observation suggests that in the milks from different animal species the peculiar coagulating substance is characteristic. From cow's milk, for example, by acid or rennet coagulation what is loosely termed "casein" is thrown down in large flakes. From

1 Read at the New Orleans Meeting of the American Chemical Society. 
human milk, on the other hand, the curd formed by acid or rennet is extremely fine, so fine indeed, that it may even be overlooked. These physical differences may be due to actual differences in constitution, or they may be due to the presence of other protein substances thrown down at the same time. In respect to this behavior with acid or rennet cow's milk and human milk seem to represent the extremes; the "caseins" of the other milks fall in between them, apparently.

This question of the nature of casein, and the relation of the substance as it exists in mother's milk to that from cow's milk is an important one from the practical standpoint, as the diffculties of providing a proper artificial milk diet for infants is assumed to depend largely on the peculiarities of the casein from cow's milk which is naturally taken as the basis of the various substitute foods prepared. Some years ago I undertook a series of experiments to determine by physical methods certain constants which might be considered as characteristic for each casein. For the time these experiments were interrupted and only recently resumed.

At the outset there is presented the problem of the preparation of pure casein, and we are confronted at once with the question of the definition of "casein" and by what general method the product should be separated from milk. In the Hammarsten method, as applied to cow's milk, the latter is largely diluted and precipitated by a little acetic acid. The supernatant liquid is poured off and the precipitate taken up with very weak alkali, preferably ammonia or sodium carbonate. This solution is largely diluted and precipitated again with weak acetic acid, these operations being repeated five or six times. The product is finally filtered, washed with water, then with alcohol and lastly with ether. The pure casein is air-dried and finally in vacuo over sulphuric acid. It holds then about 2 per cent. of moisture, which may be expelled at $105^{\circ}$.

But this whole series of operations must be carried out with great care to yield a suitable product. Not only must the acid and alkali solutions used be very weak but the operations must be quickly performed. Following each treatment a large volume of distilled water must be used, but in a prolonged contact with this water there is great danger of producing a modified or "denatured" casein which is no longer readily soluble in weak 
alkali. As a basis for the preparation it is well to use thoroughly skimmed milk. In my experiments with cow's milk I used milk from which all but about o.I per cent. of the fat had been separated by the centrifugal process. The final alcohol and ether washings, like the water washings, should be quickly performed and there is an advantage therefore in using such milk.

This general process may be applied to different kinds of milk with different degrees of success. I have succeeded in obtaining excellent products from cow's milk and goat's milk by it, but as applied to human milk the results have been less satisfactory. Besides this, it is not certain that the products obtained are quite the same as would be secured by beginning the separation with rennet and following this up with solution and reprecipitation; but for purposes of comparison I have thought it best to prepare all the products by the same process, which should be as simple as possible.

With caseins obtained as briefly outlined a number of general tests may be made, and from these a series of constants determined which will serve for comparison of different products. Among the several determinations the following may be carried out:

(a) The equivalent weight by titration with $\mathrm{N}$ / เo alkali, using phenolph thalein.

(b) The electrical conductivity of the salt solutions so obtained, and of salt solutions made with half this amount of alkali.

(c) The optical rotation of the salt solutions.

(d) The behavior of the casein on digestion with pepsin and hydrochloric acid, and the changes in the conductivity of the digesting mixture.

In what follows the results of some experiments in these directions will be given.

\section{A. CASEIN FROM COW'S MILK.}

Equivalent $W$ eight.-There are in the literature a number of determinations on this point. ${ }^{1}$ As the pure casein expels carbon dioxide Soeldner determined the amount of gas driven off from calcium carbonate. An equivalent of II 20 was found. The same author obtained an equivalent weight of 1205 by titration with lime-water or sodium hydroxide, using phenolphthalein.

1 See valuable paper by Raudnitz, in Ergebnisse der Physiologie, 2, 22 I, for many references. 
Courant found by the last method a weight of 1053. Laqueur and Sackur, ${ }^{1}$ as a mean from the titration of caseins from several sources, found an equivalent weight of II35. Other results reported differ rather widely, suggesting, probably, lack of care in the preparation of the casein used.

As a further contribution to this topic I have made a large number of titrations of three caseins obtained at different times by the Hammarsten method. These products were so pure that they furnished a very nearly clear solution in weak alkali, and could be polarized without difficulty, as referred to below. The amount of ash in these preparations was about 0.6 per cent. For each titration 5 grams (anhydrous) were weighed into a stoppered flask, about $25 \mathrm{cc}$. of carbon dioxide-free water and a little phenolphthalein were added and then $\mathrm{N} /$ ro alkali, until after thorough shaking a faint color remained. This required $44.5 \mathrm{cc}$. of the sodium or potassium hydroxide; with $45 \mathrm{cc}$. the color was always distinct. Assuming $44.5 \mathrm{cc}$. as sufficient for the reaction this gives an equivalent weight of II24. Care was always taken to exclude the carbonic acid as well as possible during the titrations. This number lies between the values given by Soeldner and by Laqueur and Sackur, but the caseins were not in either case calculated as ash-free.

By using other indicators different results are, of course, secured. The solution neutral to phenolphthalein is rather strongly alkaline to litmus. In fact, with litmus almost exactly one-half as much alkali is required for the reaction as with phenolphthalein, but the color change is not very sharp. It is possible, however, to just dissolve the casein in exactly half the alkali required for the phenolphthalein neutralization, and in this way I prepared a number of so-called acid salts.

Courant $t^{2}$ has attempted to distinguish three classes of salts which roughly might correspond to the behavior with three classes of indicators, but the practical isolation of the first class does not seem to be possible. Theoretically, salts of this class would be obtained by titrating to neutrality with lacmoid (or methyl orange), salts of the second class by titrating with litmus, while the salts of the third class are those secured by titrating to neutrality with phenolphthalein, and are the "neutral" salts

1 Laqueur and Sackur : Beiträge zur chem. Phys. Path. 3, 193.

2 Courant: Pflïger's Archiv, 50, 109. 
as above referred to. It does not follow, of course, that the salts thus obtained are really neutral. We may have here a behavior somewhat like that of the weak phosphoric acid, which in presence of phenolphthalein shows an alkaline reaction when two of the hydrogen atoms are replaced by sodium or potassium. Laqueur ${ }^{1}$ rejects the idea of Courant that there may be the three classes of salts, while Fuld ${ }^{2}$ quotes it with approval. But in any event it does not help us practically in reaching the molecular weight from the equivalent number.

Electrical Conductivity.-This important physical constant was found for a number of salts, acid and neutral. In making the so-called neutral salts (phenolphthalein) for 5 grams of (anhydrous) casein I used always $45 \mathrm{cc}$. of N/Io sodium, potassium or ammonium hydroxide and the equivalent amount of lithium carbonate. This insured good solutions which were ready for the test. The conductivities were measured all in the same small Arrhenius cell, having a capacity of 0.3 . The usual Kohlrausch method was employed with the large apparatus ${ }^{3}$ and calibrated bridge wire. A considerable degree of accuracy is possible in the measurements, and the readings with the telephone may be made with nearly as great certainty as with ordinary salt solutions. This does not seem to agree with the statement of Laqueur. ${ }^{4}$ I am unable to account for the difficulty he describes in making duplicate readings. For all the tests a temperature as nearly as possible constant at $20^{\circ}$ was maintained. Occasional slight variations were corrected by a factor found as below described.

Conductivity Tables. - In the tables given below the first column contains the concentration of the casein in grams per roo cc.; the second column the equivalent concentration of alkali; the third column gives the conductivity values $\kappa$; in the fourth column are found the values for the equivalent conductivity, $A=\frac{\kappa}{\eta}$, based on the alkali present. The weaker solutions were in all cases made by dilution of the stronger with water of a high degree of purity obtained by careful distillation and aspiration

1 Laqueur: Beiträge zur chem. Phys. Path. 7, 274.

${ }^{2}$ Fuld : Ergebnisse der Physiologie, I, 488.

${ }^{3}$ Kohlrausch und Holborn : Leitvermögen der Elektrolyte, p. 42.

4 Laqueur: Loc. cit. 
of carbon dioxide-free air through the cooled distillate. The water was stored in a flask of hard glass, and protected from the air when drawn off.

Neutral Sodium Sait, 5 Grams of Casein $+45 \mathrm{cc}$. N/to NaOH to $100 \mathrm{cc}$.

$\begin{array}{llcr}\text { Conc. casein. } & 10^{6} \eta . & \kappa_{20} . & \Lambda=\frac{\kappa}{\eta} . \\ 5 . & 45 . & 0.001787 & 39.7 \\ 2.5 & 22.5 & 0.001006 & 44.8 \\ 1.25 & 11.25 & 0.000561 & 49.9 \\ 0.625 & 5.625 & 0.000310 & 55.2 \\ 0.3125 & 2.812 & 0.000172 & 61.2 \\ 0.1562 & 1.406 & 0.000093 & 65.9\end{array}$

Acid Sodium Salt, 5 Grams of Casein $+22.5 \mathrm{cc}$. N/10 NaOH to too cc.

$\begin{array}{lccr}\text { Conc. casein. } & 10^{6} \eta . & \kappa_{20} . & \Lambda=\frac{\kappa}{\eta} . \\ 5 . & 22.5 & 0.001012 & 44.9 \\ 2.5 & 11.25 & 0.000563 & 50.0 \\ 1.25 & 5.625 & 0.000308 & 54.7 \\ 0.625 & 2.812 & 0.000168 & 59.8 \\ 0.3125 & 1.406 & 0.000093 & 66.1 \\ 0.1562 & 0.703 & 0.000050 & 71.1\end{array}$

Basic Sodium Salt, ${ }^{1} 5$ Grams Casein $+67.5 \mathrm{cc}$. N/10 NaOH to too cc.

$\begin{array}{lccr}\text { Conc. casein. } & \text { I0 } \eta . & \kappa_{20} . & \Lambda=\frac{\kappa}{\eta} . \\ 5 . & 67.5 & 0.002694 & 39.9 \\ 2.5 & 33.75 & 0.001584 & 46.8 \\ 1.25 & 16.875 & 0.000870 & 51.5 \\ 0.625 & 8.437 & 0.000480 & 56.8 \\ 0.3125 & 4.219 & 0.000264 & 62.5 \\ 0.1562 & 2.110 & 0.000144 & 68.2\end{array}$

Basic Sodium Salt, ${ }^{1} 5$ Grams Casein $+90 \mathrm{cc}$. N/to NaOH to too cc.

$\begin{array}{llcr}\text { Conc. casein. } & 10^{6} \eta . & \kappa_{20} . & \Lambda=\frac{\kappa}{\eta} . \\ 5 . & 90 . & 0.003821 & 42.4 \\ 2.5 & 45 . & 0.002170 & 48.2 \\ 1.25 & 22.5 & 0.001234 & 54.8 \\ 0.625 & 11.25 & 0.000700 & 62.2 \\ 0.3125 & 5.625 & 0.000380 & 67.7 \\ 0.1562 & 2.812 & 0.000209 & 74.4\end{array}$

1 These are called basic salts merely because of the excess of alkali in them. Nothing is assumed regarding their constitution. 
Neutral Potassium Salt, 5 Grairs Casein $+45 \mathrm{cc}$. N/10 KOH to too cc.

$\begin{array}{llll}\text { Conc. casein. } & \text { I0 } \eta . & \kappa & 1=\frac{\kappa}{\eta} . \\ 5 . & 45 . & 0.002430 & 54 . \\ 2.5 & 22.5 & 0.001350 & 60 . \\ \text { I.25 } & \text { II.25 } & 0.000724 & 64.4 \\ 0.625 & 5.625 & 0.000396 & 70.4 \\ 0.3125 & 2.812 & 0.000210 & 74.7 \\ 0.1562 & \text { I. } 206 & 0.000113 & 80.4\end{array}$

Neutral Ammonium Salt, 5 Grams Casein $+45 \mathrm{cc}$. N/ 10 $\mathrm{NH}_{4} \mathrm{OH}$ to $100 \mathrm{cc}$.

$\begin{array}{llcr}\text { Conc. casein. } & \text { I0 }{ }^{6} \eta & \kappa_{20} . & \Lambda=\frac{\kappa}{\eta} . \\ 5 . & 45 . & 0.002167 & 48 . \mathrm{I} \\ 2.5 & 22.5 & 0.001232 & 54.8 \\ 1.25 & \mathrm{I} 1.25 & 0.00067 \mathrm{I} & 59.6 \\ 0.625 & 5.625 & 0.000355 & 63.1 \\ 0.3125 & 2.812 & 0.00019 \mathrm{I} & 67.9 \\ 0.1562 & 1.406 & 0.000103 & 73.5\end{array}$

Neutral Lithium Salt, 5 Grams Casein + $\mathrm{Li}_{2} \mathrm{CO}_{3}$ Equiv, $45 \mathrm{CC}$. N/10 LiOH TO $100 \mathrm{CC}$.

$\begin{array}{llcr}\text { Conc. casein. } & 10^{6} \eta . & \kappa_{20} & \Lambda=\frac{\kappa}{\eta} . \\ 5 . & 45 . & 0.001463 & 32.5 \\ 2.5 & 22.5 & 0.000828 & 36.8 \\ 1.25 & 11.25 & 0.000461 & 40.9 \\ 0.625 & 5.625 & 0.000258 & 45.8 \\ 0.3125 & 2.812 & 0.000144 & 51.2 \\ 0.1562 & 1.406 & 0.000080 & 56.2\end{array}$

AcId Lithium Sali, 5 Grams CASEIN $+\mathrm{Li}_{2} \mathrm{CO}_{3}$ EQUiv. $22.5 \mathrm{CC}$. N/10 LiOH TO $100 \mathrm{CC}$.

$\begin{array}{lccc}\text { Conc. casein. } & 10^{6} \eta . & \kappa_{21} . & \Lambda=\frac{\kappa}{\eta} . \\ 5.0 & 22.5 & 0.000766 & 34 . \\ 2.5 & 11.25 & 0.00043 \mathrm{I} & 38.3 \\ 1.25 & 5.625 & 0.000243 & 43.2 \\ 0.625 & 2.8 \mathrm{r} 2 & 0.000 \mathrm{I} 33 & 47.4 \\ 0.3 \mathrm{I} 25 & \mathrm{I} .406 & 0.00007 \mathrm{I} & 50.7 \\ 0.1562 & 0.703 & 0.000038 & 54 . \mathrm{I}\end{array}$

Temperature Coefficient.-This was found for a "neutral" casein solution containing in $100 \mathrm{cc}$. 5 grams of casein and $\mathbf{2 2 . 5}$ cc. $\mathrm{N} / 5 \mathrm{NaOH}$

$$
\text { at } \begin{aligned}
20^{\circ} \kappa & =0.001782 \\
27^{\circ} \kappa & =0.002082
\end{aligned}
$$


For $1^{\circ}$ the difference is 0.00004286 or 2.4 per cent. of the value at $20^{\circ}$. This factor has been used, where necessary, in correcting for all the salts.

Equivalent Conductivity.-It has been suggested by Fuld ${ }^{1}$ and more definitely by Laqueur and Sackur ${ }^{2}$ that the rapid increase in the $A$ values may serve as a measure of the basicity of the casein considered as an acid, following the law first deduced by Ostwald ${ }^{3}$ and illustrated by Walden. ${ }^{4}$ According to Ostwald the change in the $A$ values for monobasic acids is about Io between the dilutions 32 and 1024 liters and approximately 20, 30,40 and 50 for the corresponding increasing basicities and same dilution limits. These conclusions are based on the assumption, however, that the acids may be sharply titrated with alkali and phenolphthalein, and that they are fully neutralized. Any conclusions drawn from the behavior of acid salts would lead to inconsistent results, as may be seen by considering the following data from tests with citric and mellitic acids by Walden. I use the true $A$ values as given in the Kohlrausch tables ${ }^{5}$ rather than the original Walden figures. ${ }^{\circ}$

\begin{tabular}{|c|c|c|c|c|}
\hline Monosodiun & itrate, & $\Lambda_{1024}$ & $\Lambda_{32} \ldots \ldots \ldots \ldots$ & $4 \mathrm{I}$ \\
\hline Disodium & " & $" 1$ & $" \ldots \ldots$ & 22 \\
\hline Trisodium & " & "i & “ $\ldots . .$. & 30 \\
\hline Monosodium & ellitate, & " & " ..... & 152 \\
\hline Disodium & ، & $"$ & ". . & 65 \\
\hline Trisodium & " & ، & ". & 65 \\
\hline Tetrasodium & " & "' & “. & 65 \\
\hline Pentasodium & “ & " & " . ................. & 67 \\
\hline lexasodium & " & " & & 57 \\
\hline
\end{tabular}

While the rule appears to work in some cases it does not in others, and the reason for the failure is not known. Walden himself does not appear to attach importance to it for acid mixtures.

The further suggestion of Laqueur and Sackur to make the relative change in the equivalent conductivity,

1 Fuld: Loc. cit.

$$
-\frac{\Lambda_{1024}-\Lambda_{32}}{\Lambda_{1024}}
$$

2 Laqueur and Sackur: Loc. cit.

3 Ostwald: Z. physik. Chem. 1, 74; 2, 901.

- Walden: Ibid. 2, 49, and later papers.

3 Kohlrausch and Holborn: Work quoted, pp. I70 and I 7 I.

- Walden: Z. physik. Chem. 8, 446. 
the measure of basicity gives somewhat more consistent results, but is still of doubtful value when applied to the citrates. The results for the mellitates are a little more regular. From the few casein solutions investigated, Laqueur and Sackur conclude that the casein must be at least tetrabasic, but may be as high as hexabasic, as they find this quotient about 0.33 .

The following table shows these relations as calculated from my observations. While they may not have much value in fixing the basicity of the salts they have some value in comparing different kinds of caseins. $A_{\mathrm{B}}$ are $A_{\mathrm{A}}$ represent the highest and lowest equivalent conductivities respectively; the range of dilution here is the same as from 32 to 1024 liters.

\begin{tabular}{|c|c|c|}
\hline & & $\Lambda_{\mathrm{B}}-\Lambda_{\mathrm{A}}$. \\
\hline & 1. $\quad \Lambda_{B}-\Lambda_{A}$. & $\Lambda_{\mathrm{B}}$ \\
\hline Neutral & sodium salt................. 26.2 & 0.39 \\
\hline is & potassium salt ............. 26.4 & 0.33 \\
\hline " & lithium salt................ 23.7 & 0.42 \\
\hline " & ammonium salt............ $25 \cdot 4$ & 0.34 \\
\hline Basic so & dium salt................. 28.3 & 0.42 \\
\hline & 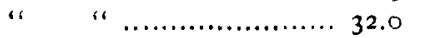 & 0.43 \\
\hline
\end{tabular}

As measured by the ratios for mellitic acid the values in the last column suggest a basicity of six. In this connection it will be noticed that the dissociation of some of the salts is nearly complete in the most dilute solutions. In the potassium salt solution the conductivity of the potassium ion would make up about 0.000093 out of $0.0001 \mathrm{I} 3$. The difference is due to the acid ion, which is present in relatively large amount, and possibly to the effect of hydrolysis, slightly. The same thing is essentially true of the neutral sodium salt solution. As the hydrolysis is not very marked, something may be learned by noting the point when, with solutions of increasing alkali content, the effect of the hydroxide in increasing the conductivity becomes apparent. Information additional to that furnished by the phenolphthalein titration may be secured in this way. In the so-called "acid" "neutral" and first "basic" sodium salt solutions the conductivities for equal sodium content are nearly equal, but in the other sodium salt there is a relative increase. A little free hydroxide adds greatly to the conductivity.

OPTICAL ROTATION.

I have already reported the experiments made with casein 
from cow's milk ${ }^{1}$ and shall merely give the values obtained for comparison.

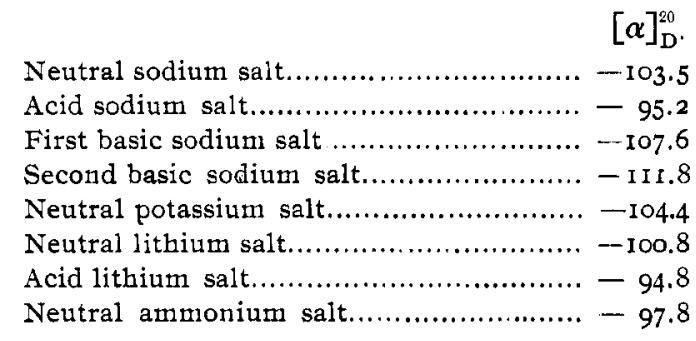

CONDUCTIVITY OF DIGESTIVE MIXTURES.

In the digestion of casein and other proteins with hydrochloric acid and pepsin a number of products are formed which differ with the protein and conditions of experiment. As some of these are basic bodies they combine with the hydrochloric acid and modify the conductivity of the mixtures materially, as has been shown by the experiments of Buzarszky and Liebermann. ${ }^{2}$ For a pure product like casein the extent of this modification of the conductivity is somewhat characteristic, as a few experiments which I have already made show. At this time, however, I shall not present any definite figures as the investigation is not complete.

What may be expected in a prolonged digestion may be inferred from the following figures. The original potassium salt solution for which $\kappa=0.00243$ was allowed to stand and undergo spontaneous decomposition, I then found $\kappa=0.01495$. In this solution the potassium alone should give a value of about 0.0028 , from which it is evident that in the breaking down of 5 grams of casein some bodies of considerable conductivity are formed. With the acid lithium salt the result was even more pronounced. The original conductivity was $\kappa=0.000766$ but after decomposition this had increased to $\kappa=0.01625$, that is, more than twentyfold. The most strongly basic of the sodium salt solutions, with the original conductivity $k=0.00382$, was heated twelve hours in a platinum dish on the water-bath and the volume made up to the original. I then found $\kappa=0.00403$, showing that a slight decomposition had taken place. After standing some weeks, for spontaneous decomposition, I found $k=0.01177$. A

1 This Journal, 27, 363 .

2 Buzarszky and Liebermann: Pflüger's Archiv, 72, 51 . 
marked change is indicated here, but not as much as in the other cases.

In the pepsin-hydrochloric acid digestion with fixed amounts of acid, uniform temperature and constant quality of pepsin, it is possible to control the changes much more perfectly and obtain results of more definite meaning, especially in the comparison of different caseins.

\section{B. CASEIN FROM GOAT'S MILK.}

This was prepared essentially as explained for the cow's milk casein, and a good product was obtained, without much difficulty. Dried in vacuo over sulphuric acid it held about 2.5 per cent. of water which could be expelled at $105^{\circ}$. In the tests below the vacuum-dried substance was always used, but in amount to correspond to the anhydrous product.

Equivalent Weight.-In these and the following tests enough was weighed out to equal 5 grams of anhydrous casein. It was found by repeated trials that the 5 grams could be dissolved in $42 \mathrm{cc}$. of N/Io alkali to make a solution neutral to phenolphthalein, both potassium and sodium hydroxides being employed. These results correspond to an equivalent weight of $\mathrm{IrgO}$, in place of I 24 as found for the cow's milk casein. This goat milk casein dissolves much more slowly in the alkali than does the other, and the final solution was always more opalescent. As with the casein from cow's milk a solution could be obtained with just half the alkali required to produce neutrality with phenolphthalein.

\section{ELECTRICAL CONDUCTIVITY.}

Two solutions only were investigated here; the results are given in the same terms employed for the casein of cow's milk.

NeUtral Sodium Salt, 5 Grams Casein $-42 \mathrm{CC}$. N/IO NaOH to IOO $\mathrm{CC}$.

$\begin{array}{llc}\text { Conc. casein. } & \mathrm{IO}^{6} \eta . & \kappa_{20} . \\ 5.00 & 42 . & 0.001694 \\ 2.50 & 2 \mathrm{I} . & 0.000942 \\ \mathrm{I} .25 & \mathrm{I} 0.5 & 0.000528 \\ 0.625 & 5.25 & 0.000297 \\ 0.3125 & 2.625 & 0.00016 \mathrm{I} \\ 0.1562 & 1.3 \mathrm{I} 2 & 0.000088\end{array}$

$$
\Lambda=\frac{\kappa}{\eta} \text {. }
$$

40.3

44.7

50.3

56.6

$6 \mathrm{r} \cdot 3$

67.1 
Neutral, Potassium Salt, 5 Grams Casein $+42 \mathrm{cc}$. N/IO KOH to IOO cc.

$\begin{array}{llll}\text { Conc. casein. } & 10^{6} \eta . & \kappa_{20} . & \Lambda=\frac{\kappa}{\eta} . \\ 5 . & 42 . & 0.002219 & 52.8 \\ 2.50 & 21 . & 0.001229 & 58.5 \\ 1.25 & 10.5 & 0.000665 & 63.3 \\ 0.625 & 5.25 & 0.000370 & 70.5 \\ 0.3125 & 2.625 & 0.000200 & 76.4 \\ 0.1562 & 1.312 & 0.000108 & 82.3\end{array}$

For both salts the $\kappa$ values stand below those for the casein from cow's milk, which should be expected from the lower amount of alkali required in combination. The dissociation constants are very nearly the same, however, being 0.40 for the sodium salt and 0.36 for the potassium salt. For the casein from cow's milk they were 0.39 and 0.33 respectively. These observations seem to relate the two kinds of casein.

OPTICAL ROTATION.

On account of the greater opalescence of the goat milk product difficulty was experienced in getting a solution clear enough to read accurately. But this was finally accomplished with the sodium salt and a series of readings were made from which I found :

$$
[a]_{\mathrm{D}}^{20}=-105^{\circ} \text {. }
$$

The same result was obtained for different solutions of the sodium salt. It is slightly larger than the value for the preparation from cow's milk.

\section{c. CASEIN FROM HUMAN MILK.}

As to the real nature of this protein there has always been some doubt. In amount it is far below the casein content of cow's milk and does not make up over I.5 to 2.0 per cent. of the whole. Relatively large volumes of the milk must therefore be operated upon to secure enough material for satisfactory tests. The experiments I have made in this direction have not, thus far, led to the desired results. The general Hammarsten process of separation is much more difficult of application than with cow's milk, and in addition, the human casein seems to become very readily insoluble in the washing and drying operations. For this reason the salts I have made have not been suitable for accurate conductivity or optical tests, and will not be reported here. 
Resumé.-The experiments cited above seem to show only one point of difference between the caseins from cow's and goat's milk and that is in the equivalent weight. The conductivities for equal amounts of alkali are about the same. The greater equivalent weight in the one case may point to the presence of a small additional complex in the casein molecule, or other small group not readily separated in the preparation, which need not exert any effect on the conductivity or rotation. The possibility of such addition groups is of ten assumed, ${ }^{1}$ and would be in keeping with the general character of the casein as a relatively strong acid. But further investigation will be necessary to settle this point.

CHicago, December, igns.

\section{THE SERIES $\mathrm{C}_{n} \mathrm{H}_{2 n-2}$ IN LOUISIANA PETROLEUM. ${ }^{2}$ \\ By Charles E. Coates. \\ Received January $\mathrm{t} t$, Igob.}

DURING the last three years, I have had occasion to examine, with some care, samples of oil from the various Louisiana oil fields. The results of these investigations showed that the oils were of an asphaltic base, with lighter hydrocarbons of the series $\mathrm{C}_{\mathrm{n}} \mathrm{H}_{2 \mathrm{n}-2}, \mathrm{C}_{\mathrm{n}} \mathrm{H}_{2 \mathrm{n}-4}, \mathrm{C}_{\mathrm{n}} \mathrm{H}_{2 \mathrm{n}-6}$, etc. These series had already been isolated by Mabery, Richardson and others. The various members were saturated, or at least did not add bromine, and had molecular refractions which did not indicate a double union. As the lowest member of this series $\mathrm{C}_{11} \mathrm{H}_{2 n-2}$ then known was $\mathrm{C}_{12} \mathrm{H}_{22}$, Mabery suggested that it was dihexahydrodiphenyl and the remaining members were its homologues. This formula seemed to agree with all the properties of these hydrocarbons and was accepted by Richardson in his recent book on the "Asphalt Pavement."

When, however, I began the examination of the crude oil from Jennings, which is the lightest of any of the I,ouisiana petroleums, I found that there was a small quantity of the very lightest fraction obtained by distillation which gave a molecular weight considerably too low for $\mathrm{C}_{12} \mathrm{H}_{22}$. From about ten gallons of the crude oil I obtained about $25 \mathrm{cc}$. of the new fraction in a fair state of purity, and found it to have the formula $\mathrm{C}_{11} \mathrm{H}_{20}$, and to

${ }^{1}$ See, for example, Raudnitz: Ergebnisse der Physiologie, 2, 217.

2 Read at the New Orleans Meeting of the American Chemical Society. 